\title{
LIGHT CURING MATTERS: FACTS OFTEN OVERSEEN BY DENTISTS
}

\author{
Dayane Carvalho Ramos Salles de Oliveira ${ }^{1,2 a^{*}}$ (i) , Mateus Garcia Rocha ${ }^{1,2 b}$ (i) , Jean-François Roulet ${ }^{1 \mathrm{c}}$ (i)
}

'Department of Restorative Dental Sciences, College of Dentistry, University of Florida, 1395 Center Dr, 32610, Gainesville, FL, USA

2Department of Restorative Dentistry, Piracicaba Dental School, State University of Campinas, Avenida Limeira, 901, 13414-903, Piracicaba, SP, Brazil

${ }^{a} D D S$, MSc, PhD, Post-Doctoral Researcher

DDDS, MSc, PhD, Researcher

'Dr med dent, Drhc, Professor, Director of Center for Dental Biomaterials

\begin{abstract}
Aim: To make dentists aware on the importance of correctly used light cure resin composites.

Method: Highlighting important facts about light curing: Use of high quality light curing unit, use of the resin composite specific appropriate radiant exposure to adequately cure a resin composite, and highlighting important facts that may alter the radiant exposure received clinically by a resin composite restoration.
\end{abstract}

Results: Application of this knowledge should change the behavior of dentists when it comes to light curing.

Conclusions: The facts described should help educational institutes and professors to reinforce proper light curing techniques and associate training sessions within educational courses in order to improve teaching and learning.

Keywords: light curing, composites, teaching.

\section{Introduction}

When placing a restoration, dentists are mainly performing a manufacturing process. This presumes good equipment, materials and process techniques. This short article will focus on the latter. A prerequisite for a proper functionality of a resin composite restoration in the oral cavity [1] is to receive sufficient radiant exposure (= irradiance of the light curing unit $x$ exposure time).

In advertisements, light curing units (LCU) are usually characterized by their irradiance, which is expressed in $\mathrm{mW} / \mathrm{cm}^{2}$. This parameter alone is, however, by far insufficient to assess the quality of light curing. It should be mentioned that currently, the range of prices for dental LCUs varies among $\$ 18.59$ (bestselling offer on e-bay on December $3^{\text {rd }} 2018$ ) and even more than $\$ 1000$. While the irradiance of lowcost and expensive LCUs may be comparable, the price difference is reflected in the homogeneity of the light beam, the diameter of the light exiting window, the collimation of the light beam, the battery management to deliver a constant radiant exposure over time (Fig. 1). Saving on the cost of a light curing unit is saving on the wrong side. It should be emphasized here that, related to the total costs of a resin composite restoration, the use of an expensive LCU does not exceed $1 \%$. This investment is worth, considering that the use of a deficient LCU may result in a poorly polymerized resin composite restoration, while the materials used will not perform as intended by the manufacturer.

Generally, manufacturers clearly indicate the radiant exposure necessary to adequately polymerize their materials (e.g. 20 seconds at $800 \mathrm{~mW} / \mathrm{cm}^{2}$ ). However, a fact that is often forgotten by dentists is to take into account the incremental thickness of the applied resin composites. Resin composites absorb, reflect and scatter the light they receive during polymerization. This means that if the maximum recommended incremental thickness is exceeded, the polymerization of the material may be insufficient, with the consequences described above. The incremental thickness recommended for most regular resin composites is $2 \mathrm{~mm}$, while for bulk fil resin composites it may be extended to 4-5 $\mathrm{mm}$. It should be emphasized that darker shades and less translucent resin composites will absorb more light and show a reduced depth of cure $(=$ incremental thickness that is adequately cured) [2].

Besides the above-mentioned reasons, the success of resin composite restorations depends on further factors [3], while the less known and most neglected factor is the light curing process [4-6]. Resin composite restorations increasingly fail due to marginal failures 


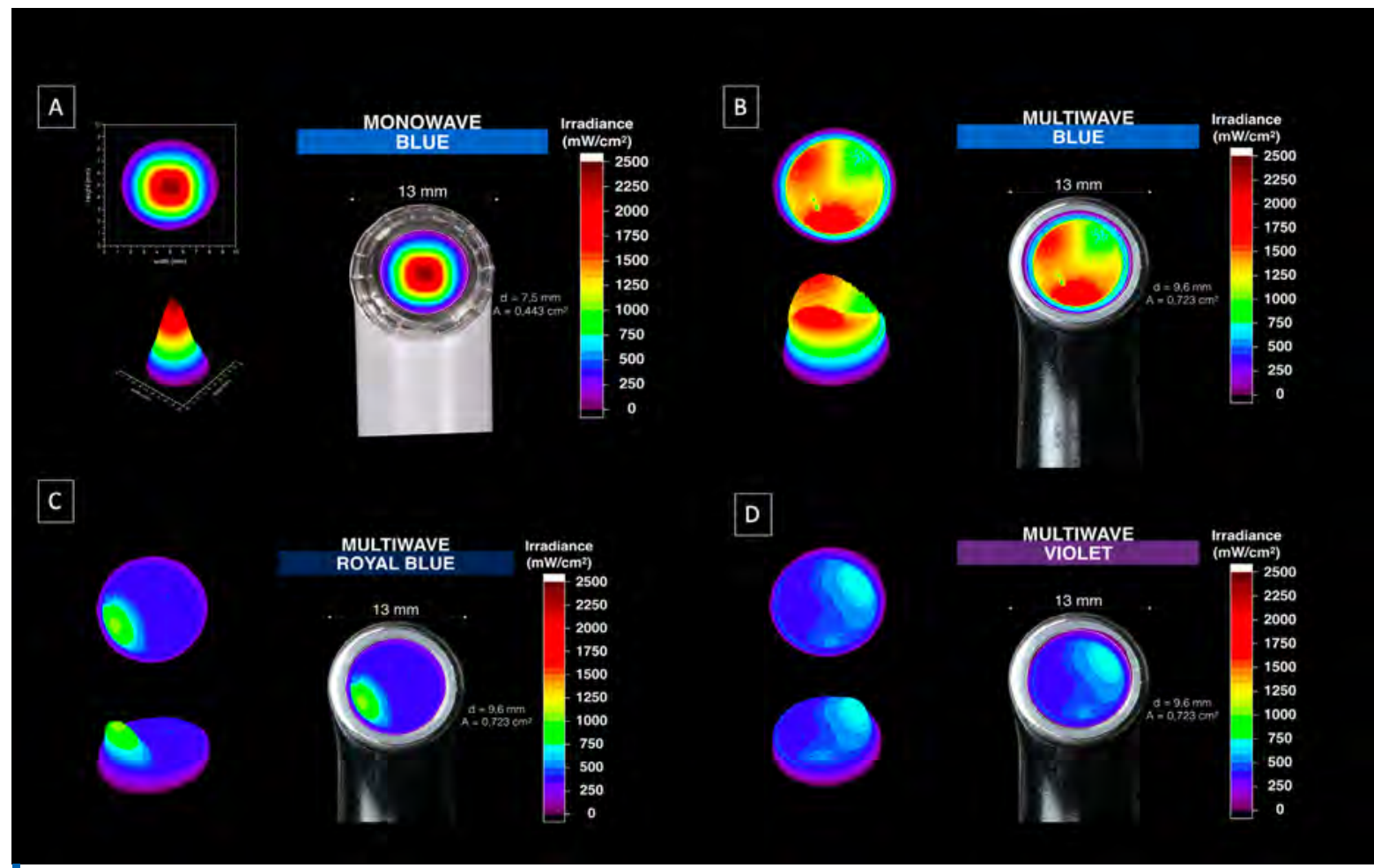

Figure 1. Homogeneity differences in light beam profile of mono- (Radii, SDI) and multi-wave (VALO Cordless, Ultradent) LED curing lights.

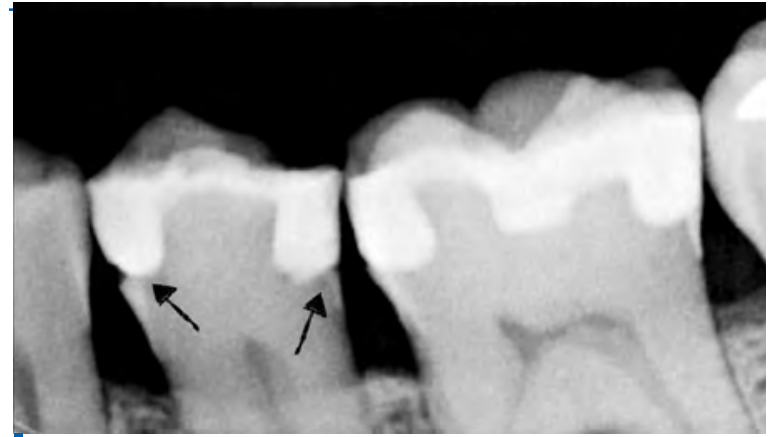

Figure 2. Marginal breakdowns due to inadequate light curing.

(Source: H. Strassler on youtube: https://www.youtube.com/watch? $v=48 X Z g R 37 \mathrm{djY}$ )

$[7,8]$, as evidenced especially in Cass II restorations, which might be found in periodical x-rays (Fig. 2). What the majority of dentists do not know is that the most common reason for this kind of marginal breakdown is inadequate light curing [9].

It is nowadays well-documented that there is a large variation between operators in delivering the radiant exposure during the light curing process of a resin composite restoration. The use of an efficient LCU is therefore not a guarantor for an adequate polymerization [5,9-11]. Fortunately, education associated with proper training was proved to be efficient to improve light curing skills (Fig. 3) [9-11].

\section{Clinical aspects}

The first important factor that can lead to improper light curing is not paying attention [9-11]. Modern curing lights emit irradiances above $1000 \mathrm{~mW} / \mathrm{cm}^{2}$ [12], thus looking into the light during polymerization is not recommended due to potential risk for ocular hazards [13-15]. In response to that, most dentists avoid looking to the patient's mouth during the light curing process.
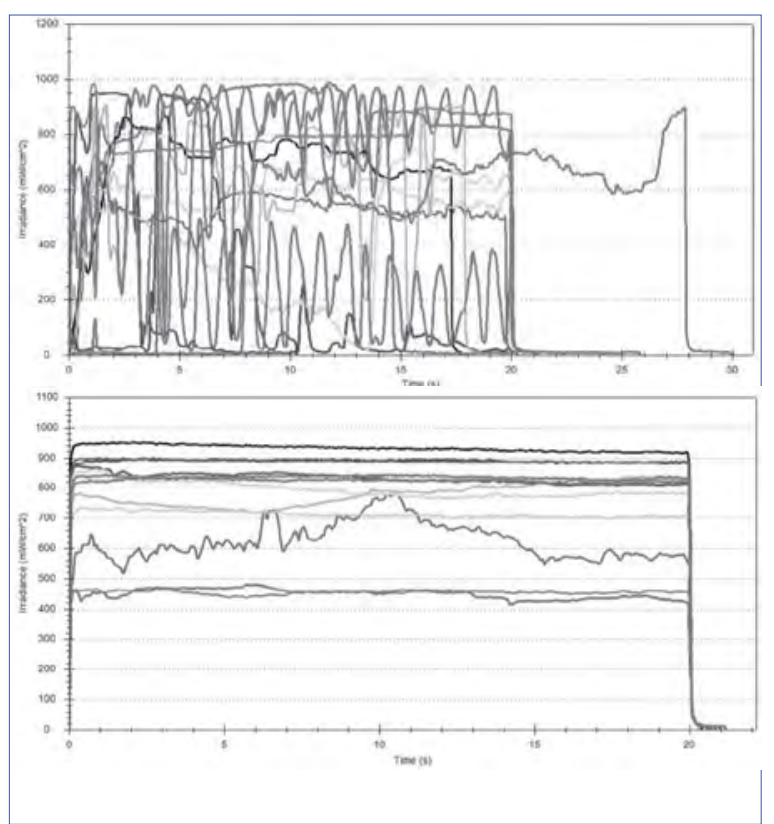

Figure 3. Light curing skills tested before and after training.

\subsection{Blue-blocking filters}

The right way to properly cure a restoration is positioning the light tip as close as possible and parallel to the restoration and stabilize and maintain it throughout the exposure [15]. In order to do so, some kind of blue-blocking shield is extremally needful. Different kinds of orange filters are available in the market to provide protection to the eyes during the light curing process (Fig. 4). These filters are able to block at least $97 \%$ of the light emitted from dental curing lights [16]. As can be observed in Fig. 5, the radiant emittance from the curing light is $1000 \mathrm{~mW} / \mathrm{cm}^{2}$, however, after interposing a blueblock filter in between the curing light emission and the sensor, the irradiance emittance from the curing 


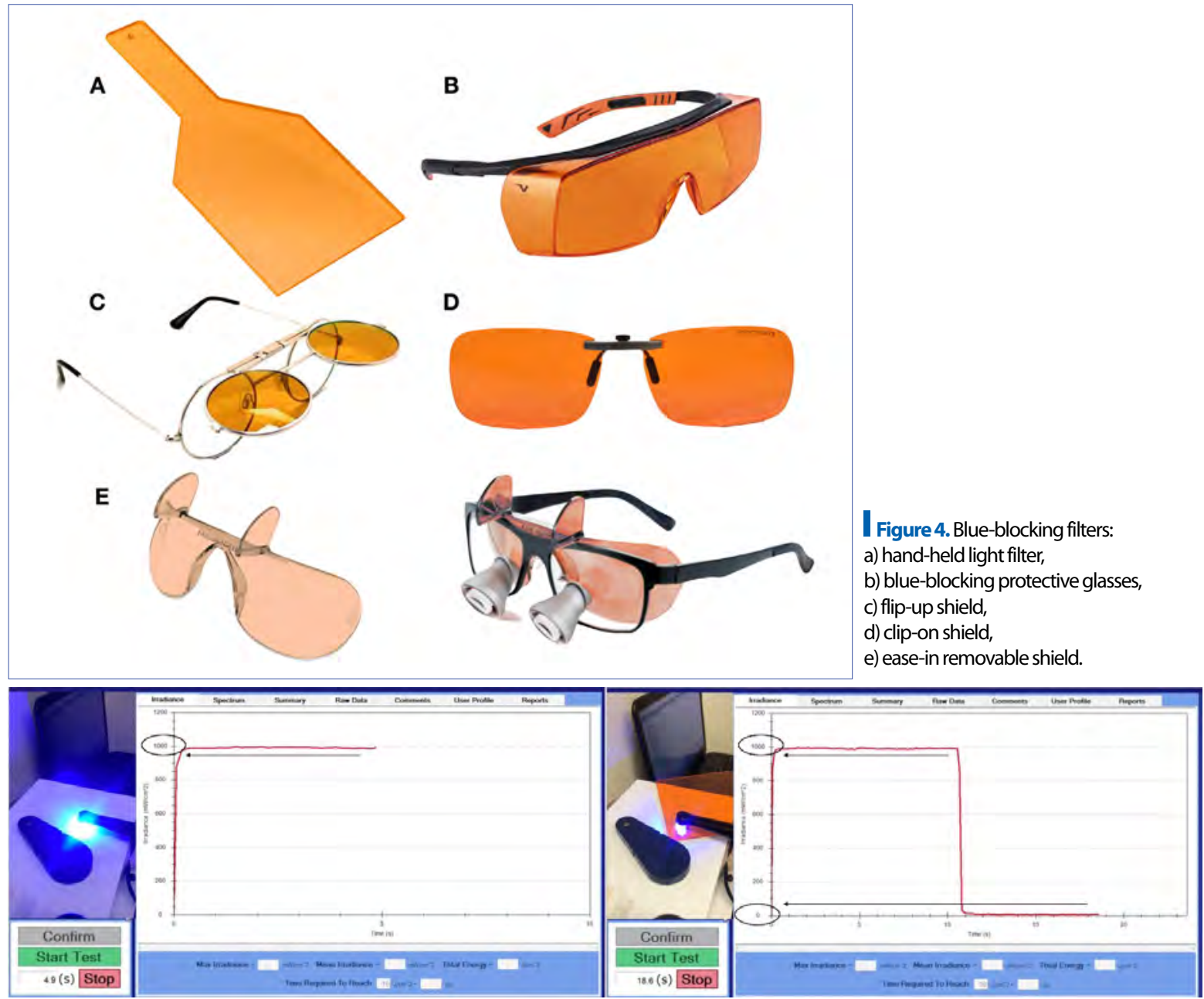

I Figure 5. Effect of blocking blue-light irradiance from a multi-wave light curing unit during light exposure.
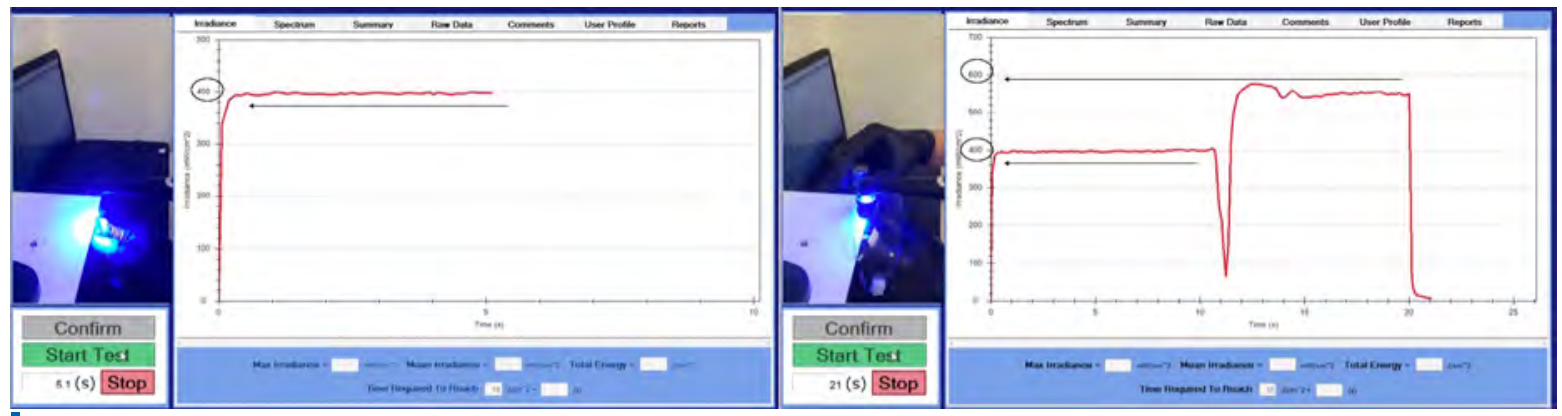

Figure 6. Irradiance increase as a result of using magnification loupes.

light is totally blocked. It is worthwhile mentioning that while using magnification loupes, the irradiance received at the pupil can be increased by up to 8 times greater than when no loupes are used (Fig. 6) [13]. Despite almost no publicity even from the own brands, blue-blocking filters specially made for loupes are available in the market, as previously illustrated in Fig. 3.

\subsection{Positioning}

The ideal case scenario is to light cure positioning the light tip as close as possible and parallel to the restoration during light curing [15]. However, different clinical situations can make this difficult or almost impossible, such as the restauration location and the light tip angulation versus patient mouth aperture (Fig. 7) [17,18].

Another aspect that cannot be neglected is that different curing lights have different light tip sizes. The light tip diameter of the curing lights in the market are between 7 and $12 \mathrm{~mm}[19,20]$. Usually fiber optic guides vary from 7 to $9 \mathrm{~mm}$ in diameter [19], while quartz lenses such as used in the VALO Cordless and VALO Grand (Ultradent, South Jordan, UT, USA) are 10 and $12 \mathrm{~mm}$ in diameter, respectively $[19,20]$. Usually pre-molar are about $7 \mathrm{~mm}$ wide, but average molars are about $10 \mathrm{~mm}$ wide (Fig. 8) [21]. Thus, special attention in positioning the curing light is encouraged when light curing proximal boxes in Class II restorations, as well as two light curing procedures in each end (mesial and distal) while using bulk fill composites in Class II restorations (Fig. 9) $[4,6,15]$.

When the light tip is not positioned properly, 


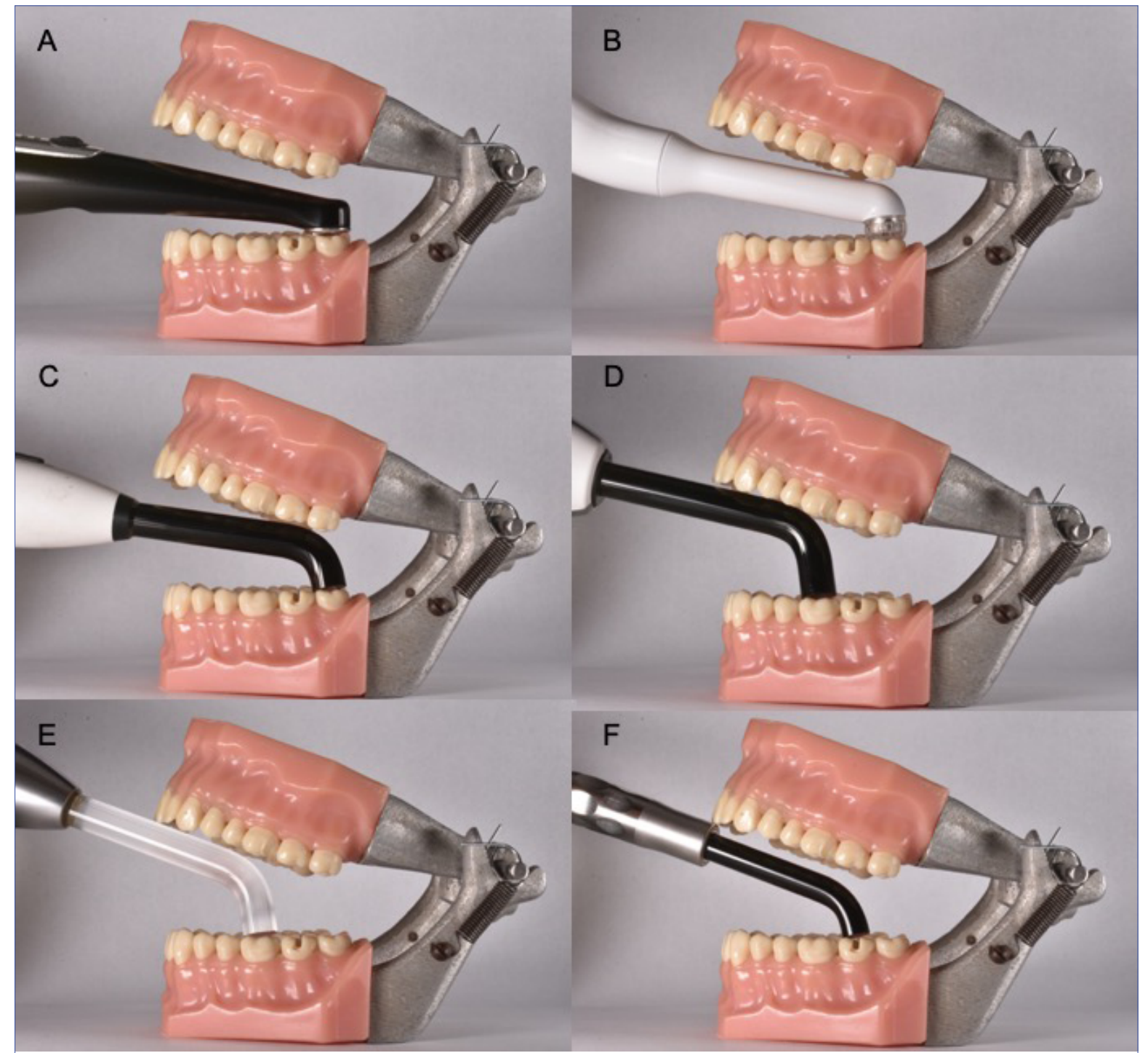

Figure 7. LCU tip angulation and ideal positioning, at same mouth aperture situation: A) VALO Cordless (Ultradent), B) Radii Plus (SDI), C) Bluephase Style (Ivoclar Vivadent), D) Bluephase G2 (IvoclarVivadent), E) Elipar S10 (3M ESPE), F) G-light (GC).

\section{Curing light tip with $\mathrm{d}=10-12 \mathrm{~mm}$}

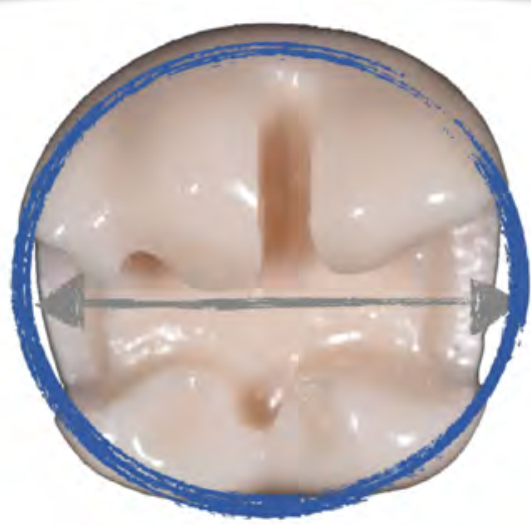

\section{Curing light tip with $\mathrm{d}=7-9 \mathrm{~mm}$}

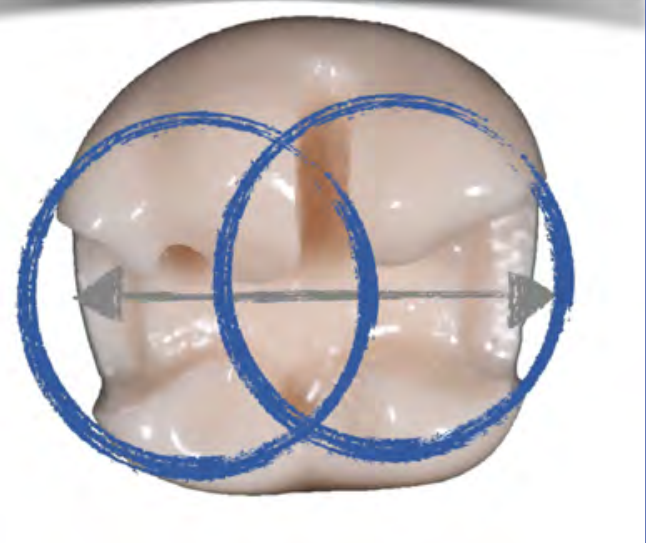

Figure 8. Overlapping ofa $10 \mathrm{~mm}$ wide molar with different light guides sizes

either because of limitations due to its size (Fig. 8) or because of angulations caused by mouth aperture (Fig. 10), not enough light will reach the resin material and polymerization can be affected [15], especially in depth, possible causing marginal breakdowns such as exemplified in Fig. 1.

\subsection{Cleaning and maintaining}

Finally, leaning and maintaining should not be forgotten. It is already known that broken and dirty light curing tips can affect the polymerization of the material [15]. Usually, when the light tip gets in direct contact with the resin composite or adhesive 


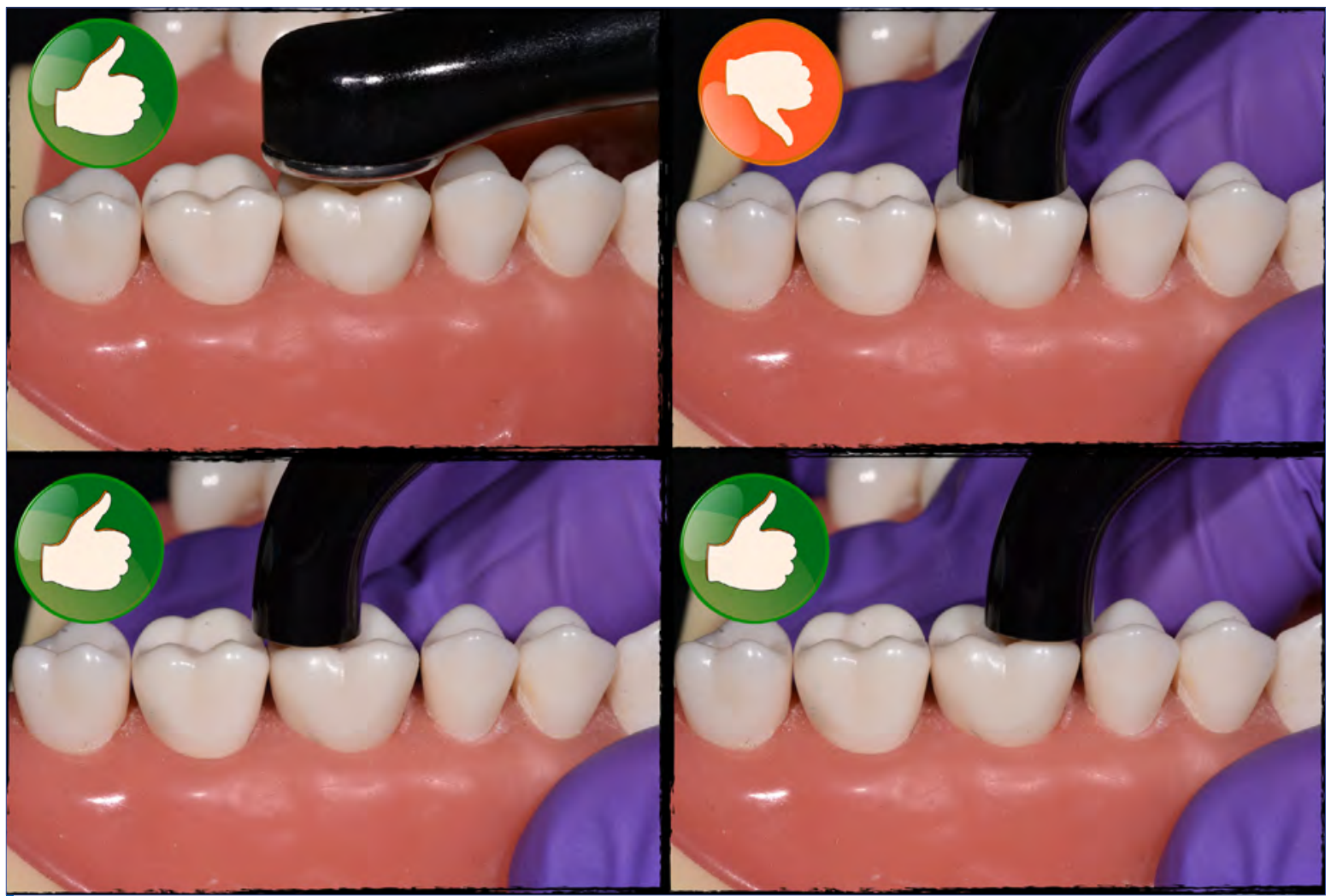

Figure 9. Instructions on light curing a $10 \mathrm{~mm}$ wide molar using different light tip sizes.
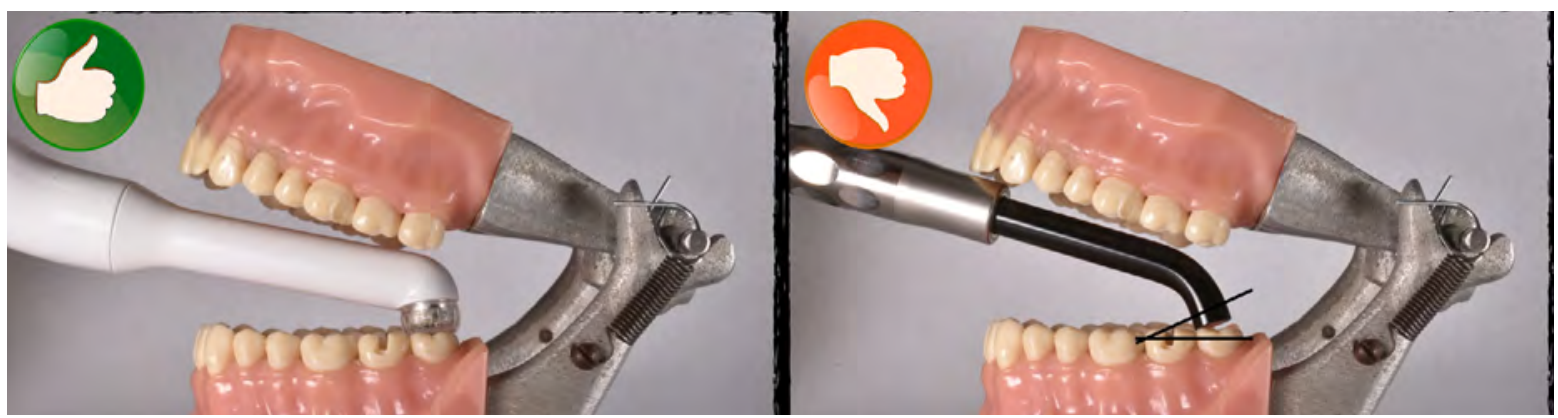

Figure 10. Instructions on positioning the curing light properly.

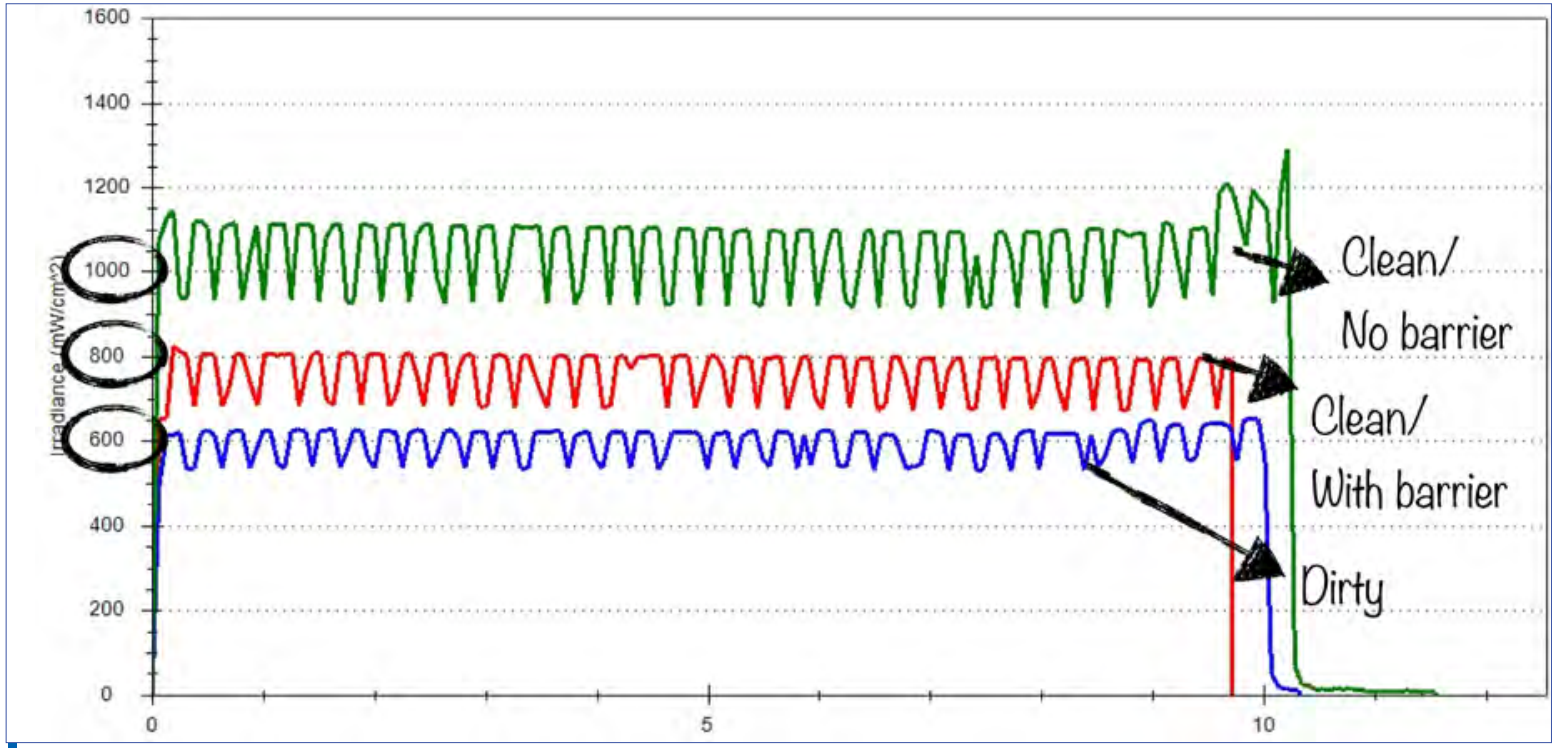

Figure 11. Irradiance emittance drop from a curing light with dirty tip and use of barrier sleeve.

during polymerization, part of this material adheres to the light tip. The problem is that not only does the restoration lose shape because part of the resin material is transferred to the light tip, but the next increment of resin will not receive the same radiant exposure than the first one. Light curing sleeves are 
not only able to protect from cross-contamination, but the light tip from resin material adhesion when accidental contact is made with the restoration during the light curing process. It is known that using light curing sleeves can cause a small reduction in the irradiance emittance from the curing light, but it is already proven not to influence on polymerization [22]. Fig. 11 illustrates an exemplification of the drop in the irradiance emittance from a curing light when no barrier sleeve is used and the light tip is clean, when the light tip is dirty and when a barrier sleeve is used. Of course, using a barrier sleeve is extremally important to protect the light tip, and guarantee proper polymerization.

\section{Conclusions}

To conclude this topic, it is worthwhile mentioning that several studies have demonstrated that the education provided to dentists and dental students seems to be insufficient to teach them how to deliver the proper amount of radiant exposure from a curing light to the restoration [9-11]. On the other hand, education associated with proper training was proved to be efficient to improve light curing skills, even in short training sessions [9-11]. Educational institutes and professors shall reinforce proper light curing techniques and associate training sessions within educational courses in order to improve teaching and learning.

\section{Author Contributions}

DO: written and proofread the manuscript. MR: written and proofread the manuscript. JFR: written and proofread the manuscript.

\section{Acknowledgments}

DO is a Post-Doctoral Researcher at São Paulo Research Foundation - FAPESP (grant \#2016/058233 and \#2017/22161-7). MR is a PhD candidate at São Paulo Research Foundation - FAPESP (grant \#2016/06019-3 and \#2017/22195-9).

\section{References}

1. Strassler H, Oxman J, Rueggeberg F. Light Curing - Tips on choosing your next curing light. CDA Essentials 2016;3:30-33. [Full text links]

2. Ilie N, Plenk E-M. Light transmission through resin composites. Stoma Edu J. 2018;5(3):148-154. [Full text links]

3. Moraschini V, Fai CK, Alto RM, Dos Santos GO. Amalgam and resin composite longevity of posterior restorations: a systematic review and meta-analysis. J Dent. 2015;43(9):10431050.

[Full text links] [PubMed] Google Scholar(64) Scopus(33)

4. Rueggeberg FA, Giannini M, Arrais CAG, Price RBT. Light curing in dentistry and clinical implications: a literature review. Braz Oral Res. 2017;31(1):e61.

[Full text links] [PubMed] Google Scholar(10) Scopus(4)
5. Samaha S, Bhatt $S$, Finkelman $M$, et al. Effect of instruction, light curing unit, and location in the mouth on the energy delivered to simulated restorations. Am J Dent. 2017;30(6):343-349.

[Full text links] [PubMed] Google Scholar(0) Scopus(0)

6. Lima RBW, Troconis CCM, Moreno MBP, et al. Depth of cure of bulkfill resin composites: a systematic review. J Esthet Restor Dent. 2018;29 [epub ahead of print].

[Full text links] [PubMed] Google Scholar(0)

7. Demarco FF, Correa MB, Cenci MS, et al. Longevity of posterior restorations: not only a matter of materials. Dent Mater. 2012;28(1):87-101.

[Full text links] [PubMed] Google Scholar(530) Scopus(307)

8. Demarco FF, Collares K, Correa MB, et al. Should my composite restorations last forever? Why are they failing? Braz Oral Res. 2017;31(1):e56.

[Full text links][PubMed] Google Scholar(10) Scopus(5)

9. Price RB, Felix CM, Whalen JM. Factors affecting the energy delivered to simulated Class I and Class V preparations. $J$ Can Dent Assoc. 2010;76:a94.

[Full text links][PubMed] Google Scholar(52) Scopus(32)

10. Price RB, Strassler HR, Price HL, et al. The effectiveness of using a patient simulator to teach light-curing skills. J Am Dent Assoc. 2014;145(1):32-43.

[Full text links] [PubMed] Google Scholar(18) Scopus(16)

11. Mutluay MM, Rueggeberg FA, Price RB. Effect of using proper light-cuing techniques on energy delivered to a Class 1 restoration. Quintessence Int. 2014;45(7):549-556. [Full text links] [PubMed] Google Scholar(17) Scopus(14)

12. Soares CJ, Rodrigues MP, Oliveira LRS, et al. An evaluation of the light output from 22 contemporary light curing units. Braz Dent J. 2017;28(3):362-371.

[Full text links] [PubMed] Google Scholar(2) Scopus(2)

13. Price RB, Labrie D, Bruzell EM, et al. The dental curing light: a potential health risk. J Occup Environ Hyg. 2016;13(8):639-646. [Full text links] [PubMed] Google Scholar(12) Scopus(8)

14. Labrie D, Moe J, Price RB, et al. Evaluation of ocular hazards from 4 types of curing lights. J Can Dent Assoc. 2011;77:b116. [Full text links] [PubMed] Google Scholar(21) Scopus(13)

15. Price RB. Light curing guidelines for practitioners: a consensus statement from the 2014 symposium on light curing in dentistry, Dalhousie University, Halifax, Canada. J Can Dent Assoc. 2014;80:e61.

[Full text links] [PubMed] Google Scholar(6) Scopus(6)

16. Soares CJ, Rodrigues MP, Vilela ABF, et al. Evaluation of eye protection filters used with broad-spectrum and conventional LED curing lights. Braz Dent J. 2017;28(1):9-15. [Full text links] [PubMed] Google Scholar(5) Scopus(4)

17. Andre CB, Nima G, Sebold M, et al. Stability of the light output, oral cavity tip accessibility in posterior region and emission spectrum of light-curing units. Oper Dent 2018;43(4):398-407.

[Full text links] [PubMed] Google Scholar(0) Scopus(0)

18. Bhatt $S$, Ayer CD, Price RB, Perry R. Effect of light and restoration location on energy delivered. Compend Contin Educ Dent. 2015;36(3):208-210.

[Full text links] [PubMed] Google Scholar(7) Scopus(4)

19. Shortall AC, Felix CJ, Watts D. Robust spectrometer-based methods for characterizing radiant exitance of dental LED light curing units. Dent Mater. 2015;31(4):339-350. [Full text links] [PubMed] Google Scholar(13) Scopus(10)

20. Shimokawa CAK, Turbino ML, Giannini M, et al. Effect of light curing units on the polymerization of bulk fill resin-based composites. Dent Mater. 2018;34(8):1211-1221. [Full text links][PubMed] Google Scholar(0) Scopus(0)

21. Babu SS, Nair SS, Gopakumar D, et al. Linear odontometric analysis of permanent dentition as a forensic aid: a retrospective study. J Clin Diagn Res. 2016;10(5):C24-C28. [Full text links] [Free PMC Article] [PubMed] Google Scholar(3) Scopus(1)

22. Scott BA, Felix CA, Price RBT. Effect of disposable infection control barriers on light output from dental curing lights. $J$ Can Dent Assoc. 2004;70(2):105-110.

[Full text links] [PubMed] Google Scholar(42) Scopus(18) 


\section{Dayane C. R. S. DE OLIVEIRA}

DDS, MSc, PhD, Researcher

Department of Restorative Dental Sciences College of Dentistry,

University of Florida

Gainesville, FL, USA

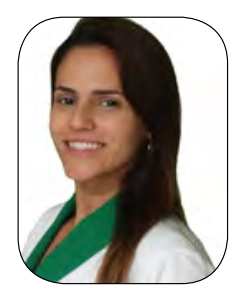

Dayane Oliveira, DDS, MS, PhD, is a post-doc fellow of the Department of Restorative Dentistry at Piracicaba Dental School State University of Campinas (UNICAMP), in Brazil, and visiting researcher of the Department of Restorative Dental Sciences at the University of Florida. Dr. Oliveira is a young researcher that contributed to 6 textbook chapters, authored 7 patents and own many awards in her area of expertise. Her areas of interest include aesthetic dentistry, color science and biomaterials development and characterization.

\section{Ouestions}

\section{Is the characterization of a light curing unit by its irradiance a sufficient parameter?}

a. Absolutely yes;

b. It tells the dentist most of the performances of the light curing unit;

ac. It only tells the user about the stability of the batteries;

$\square$ d. No, further parameters like e.g the homogeneity of the light beam should also be considered.

\section{The quality of a class II resin composite restoration depends mainly on}

$\square$ a. The brand of the used resin composite;

bb. Dentists' application technique of the light curing unit;

$\square$ c. The brand of the light curing unit;

$\square$ d. The patients' behavior.

\section{The use of orange filters are needed}

$\square$ a. To protect the dentist from eye damage during curing;

b. Only to allow dentists to better see what they are doing;

ac. To prolong the working time of a light cured composite;

$\square d$. To prevent the tooth from overheating.

\section{When light curing a resin composite restoration, dentists are recommended to:}

$\square$ a. Look to what they are doing, since this will improve the quality of polymerization, since the blue light of modern LCUs represents no risk for ocular hazards;

b. Position the light tip as close as possible and parallel to the restoration, while using blue-blocking filters;

ac. Polymerize in one-shot, irrespective of the size of the restoration and LCUs tip, to reduce shrinkage stress:

$\square \mathrm{d}$. Not to use light curing sleeves, since they induce a massive reduction in irradiance. 